\title{
An Assessment of Local Economic Development (LED) for Sustainable Development and Poverty Alleviation in Buffalo City Metropolitan Municipality
}

LINAKE, Nthekeleng

\section{Abstract}

$\mathrm{T}$ his study aims to assess Local Economic Development (LED) for sustainable development and poverty alleviation in Buffalo City Metropolitan Municipality. The main objective of the study was to investigate the catalytic role of LED strategies in Buffalo City Metropolitan Municipality and their potential to promote sustainable development and alleviate poverty. The research questions seeks to discover what LED strategies are employed by Buffalo
City Metropolitan Municipality to promote sustainable development and alleviate poverty, as well as what challenges does Buffalo City Metropolitan Municipality face in implementing LED strategies for sustainable development and poverty alleviation. The data was collected using self-administered questionnaire which were distributed to the employees in the LED department of the municipality, community members and businesses around the municipality.

Keywords: Local Economic Development, Sustainable Development, Poverty alleviation, Buffalo City, Eastern Cape, South Africa. 


\section{Introduction}

The study assesses the role of Local Economic Development (LED) in ensuring sustainable development and alleviating poverty in Buffalo City Metropolitan Municipality. It also investigates the catalytic role of LED strategies in the Municipality and their potential to promote sustainable development and alleviate poverty, and to determine perceptions on the effectiveness of LED strategies employed by the Municipality to alleviate poverty and ensure sustainable development.

Local Economic Development is there to build up the local economic capacity of a local area. This can be done by improving its economic future and quality of life for everyone. When the public, businesses and non-governmental organizations work together to create employment opportunities, there can be improved economic growth, sustainable development and less poverty in communities. Like many other municipalities all over South Africa, Buffalo City Metropolitan Municipality (BCMM) is experiencing an economic transition to a post-apartheid system. Buffalo City Metropolitan Municipality is in the Amatole District of the Eastern Cape Province, which is one of the poorest provinces in the country.

Deriving from a situation analysis undertaken development of the IDP, Buffalo City Metropolitan Municipality identified a number of challenges and constraints which impact on the way in which the municipality functions and fulfils its mandate in terms of section 152 of the South African Constitution. Challenges confronting the Metro include a declining revenue base and poor management of resources, inefficiencies that limit the manner in which the City interfaces with the communities, ageing infrastructure and deferred maintenance. BCMM is also confronted with, structural line efficiencies that result in poor service delivery standards, low economic growth and a high rate of unemployment and vulnerable environmental assets and natural resources. To address the identified challenges and work towards realization of the vision, BCMM has aligned Local Economic Development (LED) strategies as one of the tools for promoting and driving sustainable development within its areas of jurisdiction (http://www.buffalocity.gov.za/municipality/idp11/sectiona.pdf).

The main purpose of Local Economic Development is to build the capacity of a local area, to improve its economic future and the quality of life for all. Hence, LED strategies have been put forward in Buffalo City Metropolitan Municipality to reduce poverty, 
create employment, economic empowerment and to ensure sustainable development. Although a lot of work has been done in relation to the implementation of the LED and other related policies, most communities in this area are still poor and or are still living below the poverty datum line. It is against this background that this study seeks to evaluate the catalytic role of the LED strategies in Buffalo City Metropolitan Municipality and their potential to alleviate poverty, create jobs and promote sustainable development.

\section{An Overview of Local Economic Development}

The Local Economic Development (LED) strategy was not conceived in South Africa. It originated in Europe and has been successfully practised for many decades around the world. LED is not a new or innovative concept. Since 1960, LED passed through several developmental stages. The period in history records three stages, namely, 1960-1980 (agricultural investments, local and international), 1980-1990 (multi-sectorial investment attraction), and 1990-to date (shift from individual to collective conducive business). The phases show that LED is now in the third phase wherein partnerships in service delivery are imperative for socio-economic development (web.wordbank.org).

The adoption of LED in South Africa dates back to the 1990s (Helming, 2005:3). In South Africa, the adoption of the LED practice was driven by legal requirements, the socio-economic situation and the inequalities caused by the policies of the former apartheid regime (Department of Provincial and Local Government (DPLG), 2006 - 2011: 4). Given the deep-rooted effects of apartheid on South African society, an imperative was placed on the African National Congress (ANC), to commit to transformation and to promote a policy that facilitated citizens' contribution to economic development. As a result, the present ruling party in South Africa has played an essential role in terms of addressing racial reconciliation and instituting economic development, which is required to take place in a sustainable manner. The evolution of LED and its ability to adapt to societal changes can be seen as a necessary force in the South African context. The need for a South African LED strategy is justified by the advantages associated with social justice and market-driven approaches (van Schalkwyk, 2008:263)

LED is an active process that envisages a mutual relationship between citizens and local authorities so as to create development that is sustainable. In order to produce 
development that is successful, effective and sustainable, the LED plan should cover short-medium and long-term strategies. It can be stated that the strategies included in LED programmes and projects should consist of support and empowering all local communities, in particular the poor (Pillay, 2004:39).

\section{The Purpose of Local Economic Development}

The UN-Habitat (2009:1) provides the following four basic LED:

- LED is a shared process in which local citizens from all sectors work together to stimulate local business, producing a resilient and sustainable economy. It is a way to help create decent jobs and improve the quality of life for everyone, including the poor and the marginalized.

- LED encourages public, private, academic, and civil-society to establish partnerships and together find local solutions to common economic problems. The LED process tries to empower local people to effectively use business enterprise, labour, capital, and other local resources to achieve things that are important locally (e.g. to encourage quality jobs, reduce poverty, steady the local economy, and use municipal taxes to provide better services).

- LED is about sustainable development in the long term. It takes time to change local conditions, build ability, organize shared processes, and empower stakeholders, especially the marginalized and the poor.

- Creating a LED strategy is a joint process, and an effort that does not lay down laws. It uses local values (poverty reduction, increased self-reliance, satisfying basic human needs, mutual commitment, integrated social and environmental goals), uses economic drivers (growth in jobs, income, business activity) and considers development (the role of structural change, quality of development). This suggests that LED is not about quick fixes or creating a wish list. 
An Assessment of Local Economic Development (LED) in Buffalo City Municipality 155

\section{Sustainability and Local Economic Development}

According to van Zyl (1994:4) the process of economic development of a local area must have the following objectives: a sustainable development of the quality of life of people, sustained reduction of poverty levels, structural transformation of the society in terms of politics, culture and economy which leads to greater productivity, income levels and choices for people and modernization of the economy. The concepts of sustainable development and sustainability owe their origin to the World Commission on Environment and Development held in 1987.

In what became known as the Brundtland Report, sustainable development was defined as "development that meets the needs of the present generation without compromising the ability of future generations to meet their own needs" (Fakir, 2001:123). This definition stresses meeting basic needs of communities and the principle of intergenerational equity. The present generation has a responsibility to act as stewards of the environment, holding it in trust to meet current economic and social needs, while ensuring that future generations will inherit a productive, diverse and healthy environment that allows them to meet their own needs. If sustainable development is to mean that people are able to build decent lives for themselves, their families and communities, it can only start with the recognition that environmental, social and economic rights are interlinked. And it must work to protect those rights in the places where people live, work and play.

Smith \& Todaro (2003:811) articulates that sustainability relates to the quality of life in a community whether the economic, social and environmental systems that make up the community are providing a healthy, productive, meaningful life for all residents, present and future. It can be linked to providing services consistently without interruptions. Sustainable development is a pattern of development that permits future generations to live at least as well as the current generations. On the other hand, Repetto (1986:15) defines sustainable development as a developmental strategy that manages all assets; natural resources as well as financial and physical assets, for increasing long term wealth and wellbeing. Repetto (1986) further elaborates that sustainable development as a goal rejects policies that only focus on the current living standards by depleting the productive base. At the local level, it is about residents looking ahead not just twenty years, or even fifty years, but a hundred years or more and finding their communities still functioning properly. Singh, Timothy \& Dowling 
(2003:175) articulate that sustainable development calls for increased community participation, and that the rationale for sustainable development is the alleviation of poverty and the replacement of renewable natural and cultural resources.

All the above shows that when developmental issues are being discussed there is a need to take into consideration the future generation and use the available resources in a conservative manner without depriving the generations to come. It is clear that Local Economic Development strategies have to promote sustainable development and alleviate poverty. Sustainable outcomes for programmes therefore depend on two key performance indicators: the ability of the trust to manage the land as a commercial agricultural entity; and the engagement and buy-in of the claimant community as participants in this process. Despite its ubiquity in the community development literature, the concept of sustainability continues to be marginal in its impact on local public policies and programmes. Few communities have incorporated sustainability in the management of their affairs. Such avoidance seems at least partly rooted in the perception among people and government officials that sustainability is not practical, that it is utopian by nature and therefore not really very meaningful.

Mniki, (2006:4) conducted a research in Buffalo City Municipality which concentrated on sustainability in the IDP plan of Buffalo City Municipality. The study established that Buffalo City Municipality incorporated sustainability in its vision. However, there was a lack of common understanding of the meaning of sustainability. Sustainability principles featured prominently at the integrated development planning phase, but were less explicitly mentioned in the implementation, monitoring and reporting phases. Sustainability principles were subsumed in the developmental goals of the municipality but were not implemented.

The Department of Economic Development and Environmental Affairs (DEDEA) commissioned an evaluation of the LED projects in Amatole District Municipality since $2003 / 04$ to $2007 / 08$ financial years. The findings of the study confirmed the conclusions of the consultative workshops held across all of the Districts and Metropolitan municipalities. Most of the issues raised were largely a consequence of combinations of the following factors:

- insufficient guidelines for project proposers around DEDEA's expectations, 
- project selection procedures that have not been well structured, transparent, fair, objective and rigorous;

- the lack of a technical support infrastructure to ensure a successful implementation of approved projects and to build capacity for LED among local groups (http://www.dedea.gov.za/Forms/LED\%20Funding\%20Criteria).

The mechanism through which Buffalo City is preparing to meet the needs of the next decades is manifested in the Buffalo City Development Strategy (BCDS). The need for the creation of a City Development Strategy (CDS) is borne from a growing appreciation of the limitations of current development priorities and scope of municipal resources to appropriately impact on the long-term economic, environmental and social challenges faced by Buffalo City.

\section{Research Sample}

In the context of quantitative research method and scientific requirements of conducting a research study, it is necessary to identify the relevant and strategic population sample. In this study, the population sample comprised of the LED Manager, employees in the LED department, community members some of which were represented by Small Micro to Medium Enterprises (SMMEs) that contribute to the promotion of LED in Buffalo City metropolitan Municipality. The target population chosen above occupies strategic positions which were directly or indirectly associated with Local Economic Development, poverty alleviation and sustainable development in this research study. It was not possible to collect data from everyone in the categories targeted. Hence, the research was based on a portion of the target population, thus a sample was selected.

\section{Sampling and Sampling Method}

A sample is some part of a larger population, especially selected to represent the whole (Leedy \& Ormrod, 2005:198). Kumar (2005:144) elaborates more by explaining that sampling is the process of selecting a few cases from a bigger group to become the basis for estimating or predicting the prevalence of an unknown piece of information, situation or outcome regarding the bigger group; in other words, a subgroup of the population in which a researcher is interested in. The sample for the study was composed of the LED Manager, employees in the LED department, community members 
some of which were represented by Small Micro to Medium Enterprises (SMMEs) that contribute to the promotion of LED in Buffalo City Municipality. The summary of targeted respondents is presented in Table 1 below:

Table 1: Summary of respondent's sample

\begin{tabular}{|c|c|c|c|c|}
\hline \multirow[b]{2}{*}{ STATUS } & \multirow[b]{2}{*}{ POPULATION } & \multicolumn{3}{|c|}{ SAMPLE } \\
\hline & & MALES & FEMALES & TOTAL \\
\hline Led Manager & 1 & 1 & 0 & 1 \\
\hline Led Department & 10 & 3 & 4 & 7 \\
\hline Community & 15 & 6 & 9 & 15 \\
\hline TOTAL & 26 & 10 & 13 & 23 \\
\hline
\end{tabular}

Own source: 2011

Sampling theory distinguishes between probability and non-probability sampling methods. Probability sampling provides known, equal and calculable chances that each element of the population can be included in the research. Non-probability sampling suggests that chances of all elements to be included in the sample are not even and are unknown (Bless \& Higson, 2002:87). To select the sample, a non-probability sampling procedure was used. According to De Vos et al (2005:201) non-probability sampling is a sampling procedure whereby the odds of selecting a particular individual are known to the researcher because one does not know the population size of the members. In this research, the non-probability sampling techniques were used, specifically, purposive/judgmental sampling.

\section{Data Analysis and Discussion of Findings}

Leedy \& Ormrod (2005:133) articulate that the term qualitative research refers to research that focuses on how individuals and groups view and understand the world and 
construct meaning out of their experiences. Thus, this section of data analysis outlines the views of the respondents of the study. The respondents consisted of the Local Economic Development Manager, employees in the Local Economic Department and community members. The community members were represented by local business people involved in community based projects and Small Micro to Medium Enterprises. Self-administered questionnaires were used to collect data from respondents, the data received is explained below:

\section{Local Economic Development (LED) strategies employed in Buffalo City Metropolitan Municipality and their potential to promote sustainable development and alleviate poverty}

Some respondents in the LED department defined sustainable development as "triple bottom line;" i.e., economic, social and the planet. They explained that sustainable development is the effective and efficient use of the resources that the community is provided with by God so that the next generation can also use them. Thus the environment should not be destroyed and economic and social aspects of development should not be neglected. They stated that poverty alleviation is a central issue for BCMM and is addressed, within the available resources, through various IDP programmes and projects. Examples of these include BCMM's LED programme, the provision of free basic services to qualifying households and the Mdantsane Urban Renewal Programme.

Most respondents in the LED department including the LED manager outlined some of the important LED strategies they use in the municipality to promote sustainable development and to alleviate poverty. Generally, the respondents defined these to include trade and development, the Industrial Development Zone (IDZ), Buffalo City Development Agency (BCDA), Tourism and Small Medium and Micro Enterprises, the Agricultural Development Strategy and the Informal Development Strategy. These strategies are believed to have a great impact in promoting sustainable development and poverty alleviate. They are summarized below:

\section{Trade and Investment}

The respondents were of the view that Trade and Investment Promotion seeks to keep up a significant and sustainable economic growth that is necessary for job creation by: 
- identifying the key constraints on growth (e.g. red tape) and helping businesses overcome those attracting and facilitating domestic and foreign direct investment into the BCMM area,

- $\quad$ establishing networks with the international business community,

- assisting business growth by promoting effective linkages between large businesses, IDZ and emerging businesses,

- aligning business development and growth strategies with national and provincial government strategies.

Despite its strategic importance, the Programme Manager admitted that Trade and Investment Promotion face various challenges. Its biggest challenge is that, the unit's capabilities were limited in recent years due to capacity and financial constraints.

\section{The Industrial Development Zone (IDZ)}

According to the employees in the LED department, the Industrial Development Zone (IDZ) is an important part of the economic infrastructure of East London. The IDZ is jointly owned by the Eastern Cape Development Corporation (74\%) and BCMM (26\%). The goals of the project are to bring economic growth to the region and beyond by offering investors a globally competitive combination of geographic position, infrastructure, services and labour. The IDZ is seen not only to offer investment opportunities, but also to play a pivotal role in the support of the Black Economic Empowerment.

\section{Buffalo City Development Agency (BCDA)}

Another respondent in the department was of the opinion that one of the institutional vehicles created to advance and leverage the development of potential investment opportunities inherent in various area-specific parts of the city is the Buffalo City Development Agency (BCDA). The mission of the Agency is to increase the prosperity of Buffalo City and its citizens through the identification of under-realised property assets in public ownership and the facilitation of their development by partnerships involving municipal, business and community actors. Its first area of responsibility is the East London beachfront and Quigney areas where their mandate is to ensure that the 
economy of these areas achieves its full development potential through the promotion and support of existing strengths and new opportunities.

\section{Tourism}

One of the respondents was of the opinion that tourism has increased steadily in Buffalo City Metropolitan Municipality specifically in East London. However the respondents generally noted that surrounding regions such as Mdantsane, King Williams Town and Bisho have a limited tourism sector. He suggested that there should be more activities such as heritage and culture promotions in these areas in order to create employment.

\section{Small, Medium and Micro Enterprises (SMMEs)}

The LED programme manager stressed that one of the municipality's goals is to facilitate community level and strategic economic empowerment through working in partnership with the private sector to achieve the following objectives:

- improve black economic empowerment by development of small businesses, particularly those owned and operated by previously disadvantaged persons,

- delivering targeted SMME support programmes through the Mdantsane OneStop Shop, Business Place eQonce and the Duncan Village Business Hives (under construction),

- facilitating training and skills development for SMMEs and promoting job creation opportunities.

Some community members involved in SMMEs admitted that the municipality has indeed assisted them in registering their businesses and provided them with training on ways to improve their businesses. Other respondents who are foreigners complained that they do not get any assistance with their businesses from the municipality since they are foreigners.

\section{The Agricultural Development Strategy}

The last strategy which is used by the municipality is the agricultural development strategy which seeks to provide the following opportunities for agricultural development within Buffalo City: 
- dairy,

- tunnel farming,

- essential oils,

- fat lamb production,

- strawberry production and timber production.

The respondents were not clear about how this strategy is implemented, to whom and how effective it is. It is thus critically important that more research be carried out to investigate the impact and or effectiveness of these poverty alleviation tools.

\section{Informal Sector Development Strategy}

According to most respondents in the LED department, the Informal Sector Development Strategy is targeted towards second economies which are hawkers and other street traders. These programmes include provision of business skills training, registration of businesses, understanding of municipal by-laws and provision of trade stalls. When the community members were asked about the LED strategies used to promote sustainable development and alleviate poverty, most of them only mentioned agriculture, SMMEs and tourism. This is thus reflective of the limited innovative insights among community members as to the various mechanisms and strategies that may be employed in poverty alleviation.

\section{The effectiveness of LED strategies employed by Buffalo City Metropolitan Municipality to alleviate poverty and promote sustainable}

One respondent in the LED department was of the opinion that some of the strategies, such as the Informal Sector Development Strategy, have been very effective in implementing its objectives. According to the respondent since the 2008/2009 financial year, BCMM has provided equipment worth R4 million to primary cooperatives within the city. The municipality has also provided fifty-five (55) hawker stalls to the informal traders in Mdantsane, East London and King Williams Town. Most respondents were of the opinion that the strategies are effective to a certain extend. They argue that the municipality is faced with a number of challenges when implementing their strategies. 
These challenges include limited resources both human and financial resources, the inability for the projects to reach the society as a whole and the fact that Eastern Cape is one of the poorest province in South Africa, creates economic development challenges.

Some respondents in the department articulate that some strategies are not implemented effectively due to the following challenges:

- shortage of finance to implement programmes,

- shortage of staff in the department, and

- Supply Chain policies that are not friendly to the procurement of goods and services from SMMEs.

They explained that the shortage of finance results in the department not being able to implement the programmes as outlined in the Economic Development Strategy. Access to adequate funding according to most respondents remains a problem for many local authorities, particularly as the funding application process to central government departments is exceedingly time consuming. In most cases, the budget allocated to the municipality is insufficient taking into consideration basic priorities and needs of the communities it is intended to serve.

The shortage of staff limits the implementation of certain programmes in terms of results. This often results in the department having to engage consultants to do some of the work. Regarding Supply Chain Management policies, sometimes there are no financial resources to support SMMEs; hence this increases the unemployment rate. There are a number challenges facing SMMEs, these include limited capacity and experience, streamlined services, and a culture that failed to recognise entrepreneurship as an initial option.

Others stated that even though BCMM is a large metropolitan municipality, the budget allocated to the municipality is not enough to implement the LED strategies. Some employees in the LED department stated that they were still confused about their roles in LED. They argued that the sole responsibility of LED is put on local government and ignores other important actors such as businesses and civil society organizations (CSOs). In order for LED strategies to be effective, the municipality, community, businesses and investors should all work together to make it a success.

Lastly, one of the respondents stated that the municipality is still working hard to attract investment and form partnerships to assist in the effectiveness of Local Economic 
Development, since there is still ample poverty and unemployment in the municipality. The respondent stated that identifying funding and supporting small businesses remains challenging and complex. High failure rates amongst start-up businesses are common, due to a lack of business skills among community members. Some business managers were viewed by the respondents as weak, thereby leading to weak foundations of the businesses as a whole.

\section{Community members' perceptions on the municipality's LED efforts and initiatives for promoting sustainable development and poverty alleviation}

The community members were represented by local business people involved in community based projects and managers and employees involved in Small Micro to Medium Enterprises (SMMEs). Most Community members had different views on the municipality's efforts for promoting sustainable development and alleviating poverty. Some respondents were of the view that there are a number of support organisations which exist for the SMME sector in the municipality such as the Border-Kei Chamber of business, the Business place and Khula Enterprise Finance which have assisted community members in developing their businesses.

These organizations have helped people to be independent and earn their own money and not to depend on government grants. Some community members were involved in the Small Projects Foundation, which assists in providing community projects such as farming and building hawker stalls to help alleviate poverty. Others mentioned that the municipality has assisted them in registering their businesses, Business Plan preparation and Tender advice. Another respondent stated that the municipality supported only a small portion of the local businesses, while the majority were on their own.

Most respondents stated that the unemployment rate in the municipality is still high; the employment opportunities are not enough for the majority of the population. They also stated that there is little public participation on the formation of strategies used to promote sustainable development and alleviate poverty. Some respondents involved in community based projects complained that the projects were not sustainable and did not raise enough money for them to alleviate poverty and support their families. There is 
a need for the development of sustainable local businesses in the municipality. Others were of the opinion that they were not well informed about community projects and organizations that can assist them. Some respondents were of the view that strategies employed by the municipality only create opportunities to those who were already in businesses. They argued that there are few projects for people who are unemployed, since most of them lack financial capital. Coupled with this, the majority of the people, who can potentially benefit from LED do not have the necessary skills and education to carry out the projects, hence some of the projects fail.

\section{RECOMMENDATIONS}

The following recommendations are therefore put forward for consideration by Buffalo City Metropolitan Municipality and to possibly assist the municipality in implementing its Local Economic Development strategies effectively to promote sustainable development and alleviate poverty:

- There should be short training courses to provide some employees in the LED department, local actors and the community with a better understanding of LED and the different roles they should play in LED.

- To effectively increase business activity and provide employment benefits, local economic development programmes need to include customised training and skills development programmes that can effectively serve the needs of the business community and the unemployed. There should also be entrepreneurship training programmes to provide training in developing business, marketing and financing plans. This training should be aimed at disadvantaged groups, such as the unemployed, women and minorities.

- The government should increase LED funding and implement more projects that will benefit a large number of people in the municipality.

- There should be more staff members employed in the LED department to coordinate and monitor the implementation of community projects.

- Local economic development should be focused on providing employment and fiscal benefits to local residents, while preserving the local quality of life for all. 
- Everyone in the municipality should work hand in hand to ensure effectiveness of the LED strategies. This is because while local municipalities are mandated by the Constitution to "promote social and economic development", they will not be able to do this without clear policy guidance; institutional capacity-building; inter-sectoral collaboration; community members to drive the process; and real empowerment of the beneficiaries whom the projects are supposed to assist.

\section{Conclusions}

Conclusions drawn from the study are the following:

- The results obtained indicated that despite the municipality's Local Economic Development initiatives, there is still low economic growth and a high rate of unemployment in the municipality. This further translates to relatively low levels of development of Buffalo City Metropolitan. This is coupled with generally lack of appropriate education and skills levels. A significant portion of the Metropolitan's potential labour force have not attended school or completed their primary schooling phase.

- The challenges facing SMMEs include limited capacity and experience, streamlined services, and a culture that failed to recognize entrepreneurship as an initial option. The above factors underestimate the importance of small business enterprises, and thus the shortcoming is the limited attention to building the capacity of employees within these business enterprises. Management and skills development have also been targeted as a shortcoming of SMMEs in the BCMM. Weak management has a detrimental effect on an enterprise, as the foundations of the business will be unstable.

- The municipality has success stories in building businesses in the informal sector such as hawker stalls. Community members still complain that these businesses are not sustainable. There is a need for the development of sustainable local businesses. 
- The municipality has many Local Economic Development strategies and it has managed to form partnerships with other stakeholders to provide employment opportunities. There are success stories in some areas and failures in others.

- The main reasons why the municipality has been unable to effectively carry out all its Local Economic Development strategies, generally relates to a lack of financial resources and a shortage of human capital.

- Sustainable development is a concept that has been considered by all organizations and agencies who participated in this research and it stresses the importance of the economic, social and environmental aspects in order to ensure the development of future generations.

\section{List of References}

- Babbie, E. and Mouton, J. 2001. The Practice of Social Research. Cape Town: Oxford University Press.

- Bak, N. 2004. Completing thesis: A practical guide. Pretoria: Van Schaik.

- Bless C. and Higson-Smith, C. 2002. Fundamentals of Social Research Methods: An African Perspective. Lansdowne: Juta.

- Bryman, A. (2004). Social Research Methods (2nd Ed). Oxford University Press Inc: United States of America.

- Buffalo City Development Strategy Consolidation Report Version 4.1. 2007. Available on http://www.Buffalocity.gov.za/files/documents/21070911322.pdf. Assessed on: 23 March 2011.

- Buffalo City Municipality: Available on http://www.Buffalocity.gov.za. Assessed on: 20 March 2011.

- $\quad$ Fakir, S. 2001. The Summit in South Africa. New Agenda. 4:123-130.

- Leedy, P.D. \& Ormrod, E.J. 2005. (8th ed). Practical Research: Planning and design. New Jersey: Pearson Prentice Hall. 
- Mniki, C.P. 2008. An analysis of the implementation of sustainability principles in Buffalo City Municipality. Masters' Thesis: Rhodes University.

- Mouton, J. 1996. Understanding social research. Pretoria: J. L Van Schaik.

- Pierce, R. 2008. Research Methods in Politics: A practical guide. London: Sage Publications.

- Sarandakos, S. 2005. (3rd ed). Social Research. London: Palgrave-Macmillan.

- Singh, S., Timothy, D.J. and Dowling, R.K. 2003. Tourism in destination communities. Oxford: CABI.

- Smith, S. C and Todaro, M.P. 2003. (8 $8^{\text {th }}$ Ed). Economic Development. London: Pearson.

- UN-HABITAT. 2009. Promoting Local Economic Development through Strategic Planning Volume 5: Trainer's Guide. Nairobi: UNHABITAT.

- Van Schalkwyk, A. 2008. Sustainability of Service Delivery in Municipalities in South Africa. Journal of Public Administration, 43 (2.1): 263, 266.

- Welman, C., Kruger, F. \& Mitchell, B. 2005. (3rded) Research Methodology. Cape Town: Oxford University Press Southern Africa (Pty) Ltd.

\section{AUTHOR'S CONTACT:}

NTHEKELENG, Linake

School of Public Administration

University of Fort Hare

Email: nlinake@ufh.ac.za 